\title{
Improving Conviviality in Public Places: The Case of Naples, Italy
}

\author{
Gabriella Esposito de Vita ${ }^{1}$, Carmelina Bevilacqua ${ }^{2}$ and Claudia Trillo ${ }^{3}$ \\ 1. IRAT National Research Council of Italy (CNR), Naples 80134, Italy \\ 2. Department of Heritage, Architecture, Urban Planning (PAU) University Mediterranea, Reggio Calabria 89124, Italy \\ 3. School of the Built Environment (SOBE), University of Salford, Salford M54WT, UK
}

\begin{abstract}
Under the umbrella concept of conviviality in public spaces, a research project on the rehabilitation of urban areas for commercial and retail uses_-as engine of a complex process of production of places for social and cultural mixité-has been defined. The aim of this research has been to produce useful tools for coping with the abandonment of public spaces in former commercial urban areas, without generating anonymous and globalized commercial districts. Through involving local stakeholders in a participatory process, the first phase of the research here presented needs to demonstrate the possible effectiveness of a pilot action plan in dealing with both isolation and gentrification processes of historical centres. The main hypothesis is that traditional retailers should be considered an essential element to ensure effective public use of urban public spaces. The research methodology is based on a qualitative approach. Focussing on the process of impoverishment within local commercial districts, the research group started working with local stakeholders in order to identify priorities and criticisms for enhancing a regeneration process. The case study to be carried out in Naples is the historical market place of Piazza Mercato in the Città Bassa of Naples (Italy).
\end{abstract}

Key words: Public places, traditional retail areas, urban regeneration, historical centres, conviviality, Naples.

\section{Introduction}

The contemporary city is affected by a profound crisis due to the loss of cultural identities, of traditional social networks and of welcoming urban spaces for improving interactions between diverse components of society [1]. Places of public life are the expression of this scenario: the agora is changing forms, functions and symbols, following new trends superimposed by globalization phenomena [2]. The impact on the transformation of public places due to recent dynamics, is revealed by the tendency to produce market-led transformations of public places in affluent areas and the abandonment and decay of the peripheral public realm [3].

In the following pages, a research project will be presented which is aimed at identifying the main components of a process of rehabilitation of urban

Corresponding author: Gabriella Esposito de Vita, Ph.D., researcher, research fields: urban design, community planning and social activation. E-mail: gabespo@unina.it. areas for commercial and retail uses in order to favour social and cultural mixité and economic regeneration. The project deals with the increasing globalization process, and consequently with the expulsion of traditional and identitarian commercial activities from the city centre, creating ruptures in the continuity of the urban grid in terms of creation of market-led and anonymous commercial areas on the one hand, and in terms of abandonment and decay of less affluent areas with a strong local cultural character on the other [4].

The research starting point is the role played by traditional retailers and artisans as an essential element to preserve local cultural character, ensuring effective public use and liveability of urban public spaces. The privatization and commercialization of public and quasi-public places in affluent or well-connected areas of the city, on one hand, and the decay and abandonment of public places in deprived areas, on the other hand, they are both causes and effect of the social transformations. Economic crash, 
transformation of the job-market, dynamics and quantities of migratory flows are strictly related to the tendency of living in gated communities and privatized public places dedicated to a forced conviviality. The idea of convivium could be the umbrella concept for surveying, interpreting, assessing, designing, managing public spaces as places of multicultural identity, security and security perception, democracy and discussions, ethic and aesthetic and human development [5]. This qualitative approach aims at defining a holistic methodology for interpreting, designing, managing and assessing the refurbishment and redevelopment of those specific areas. This topic will be addressed by developing an urban design tool based on an effective participatory process in the rehabilitation and redevelopment of public places in abandoned commercial areas [6]. This tool could be applied within community planning consolidated methods [7-9], in order to better address the physical and spatial component of the mapping and visioning process. Consolidated procedures for collecting and sharing the demand expressed by local communities in terms of services delivery and public places organization have been developed in different fields of knowledge [10]. Nevertheless, there is a lack of procedures for addressing demand for spatial transformations in order to favour the preservation and development of traditional and identitarian artisanal and retail areas as a driver for a wide urban regeneration process [11].

In order to identify the way physical and functional transformations of commercial areas in city cores can favour results in terms of social cohesion, economic development, cultural preservation and local liveability, the study started by working with a case study approach [12].

The research focuses on the specific experience of Naples in southern Italy, which offers a wide range of interesting fields of reflection on the research topics. The group of scholars and local technicians involved in the fieldwork started doing active observations of the Neapolitan urban area in order to identify possible significant case studies to be carried out. The conceptual map of significant areas was discussed with local key actors such as: academics in the field, technicians involved in the urban planning and management, members of the local governing bodies, activists from local NGOs (non-governmental organizations) involved in topics such as job creation, civic activation and urban regeneration as well as local communities. The discussion resulting in the selection of the historical market place of Piazza Mercato and its neighbourhood in the Città Bassa district as a case to be analysed because of the specific issues related to artisanal and retail traditions combined with the abandonment of public places and the impoverishment of economic activities on the one hand, and because this area has been the core of the Local Action Plan implemented within the framework of the CTUR and Hero Projects of the URBACT II Programme.

The fieldwork has been developed according to the rationale of the EU-funded research "Commercial Local Urban District Programme" led by the PAU of the University Mediterranea of Reggio Calabria (IT) "aimed at emphasizing the strategic role of small retailers - handcraft and typical food - in reinforcing the sense of community, reducing transportation costs and contributing to the creation of an attractive urban environment, thus producing an increase in private investment" [13].

Through the experience gained during the execution of the Local Action Plan for this historical area in southern Italy, this paper aims at introducing and discussing a work in process oriented to coping with the tendency to abandon wide core areas of the city centre by supporting virtuous processes of urban regeneration, and intervening through a participatory process in the rehabilitation of traditional and natural market areas.

This paper is divided into four sections. Having introduced the research in this section, the following three sections aim to: 
- Set the context to identify the theoretical and methodological context of urban design, community planning and economic procedures to be applied together to commercial urban districts regeneration;

- Define the framework for the empirical analysis and discuss the pilot area findings;

- Draw general conclusions, defining the role of local commercial areas as divers of urban regeneration.

\section{Setting the Theoretical and Methodological Context}

Every city is a human creation, but only a few cities-in certain historical moments-have developed a successful expression of public spaces as trans-community agora suitable for liberating identity. In those cases, cultural cross-pollinations have led to the creation of particular architectural and urban forms, which generate a physical-functional-relational milieu [14].

"Public space, if organized properly, offers the potential for social communion by allowing us to lift our gaze from the daily grid, and as a result, increase our disposition towards the other" [15]. Shared spaces have played, on the one hand, the role of symbols of collective well-being and formation of civic culture and, on the other hand, of agonistic struggle and social conflicts. "In an age of urban sprawl, multiple usage of public space and proliferation of the sites of political and cultural expression, it seems odd to expect public spaces to fulfil their traditional role as spaces of civic inculcation and political participation" [15].

The history and culture of European cities reveal the importance of public spaces such as streets and squares, which are deeply influenced by the commercial functions they host. Over the centuries, local retailing models, often integrated with the production of typical services, handcraft traditions and locally produced food, have frequently conditioned forms and organization of the European city (Fig. 1). More generally, a higher level of manufacturing, commercial and residential integration, is still related to vibrant urban environments, which are rich in urban life and social relations [16]. The contemporary public space is the urban place that, more than others, has been influenced by recent transformations of production-related activities and of human behaviors, spatial codes and use models of public spaces-for a long time completely unchanged - have been affected by the acceleration of the dynamics of the urban system [17]. In accordance with Habermas' observation that "public spaces become the object of practices of cultural representation, with which the public sphere is arguably more and more concerned" [18], the research deals with the holistic idea of public places as an expression of the cultural gaps within a conflicting society and, at the same time, as place for improving conflict-solving practices by favoring public gathering. The first node to be tackled is the lack of a shared vocabulary concerning the recent expressions of public spaces, of private spaces with a public use and of public spaces with a private use [19-22]. Some provocative questions could be evoked, as the editors did in Architecture and Dispersal: "What constitutes public space in the contemporary city? Can the public sphere still exist in the urban context? Should public space be fought for by architects and urban designers?" [23]. The everyday use of public space has been changing from necessary uses to optional, recreational uses. This changing role increases the need for appropriate, well-designed places in which people choose to spend time, and that provide a place for people to relax, socialize and be part of urban life" [24].

From the social point of view, it is widely recognized that integrated urban environments often contribute to a higher level of safety because of the social control exercised on the public spaces due to their continuous use, for the same reason, they are less likely to became blighted areas, thanks to the involvement of local communities in preserving their values $[25,26]$. 


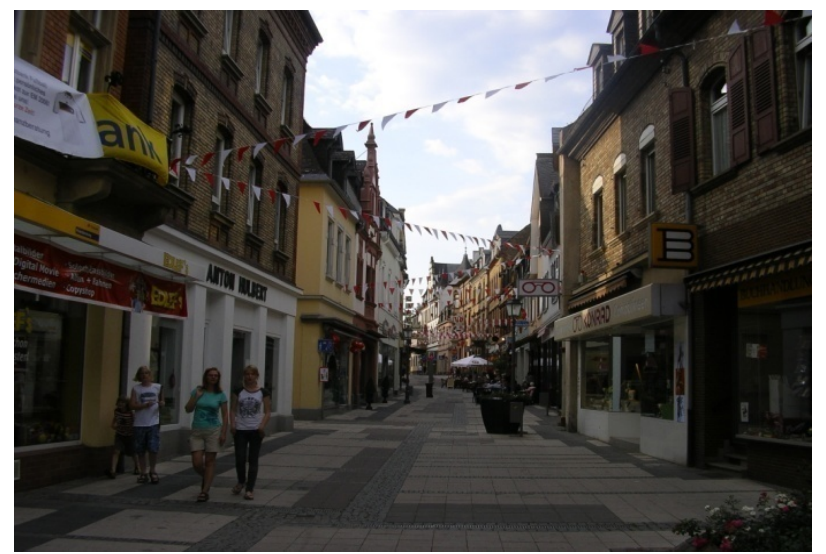

(a)

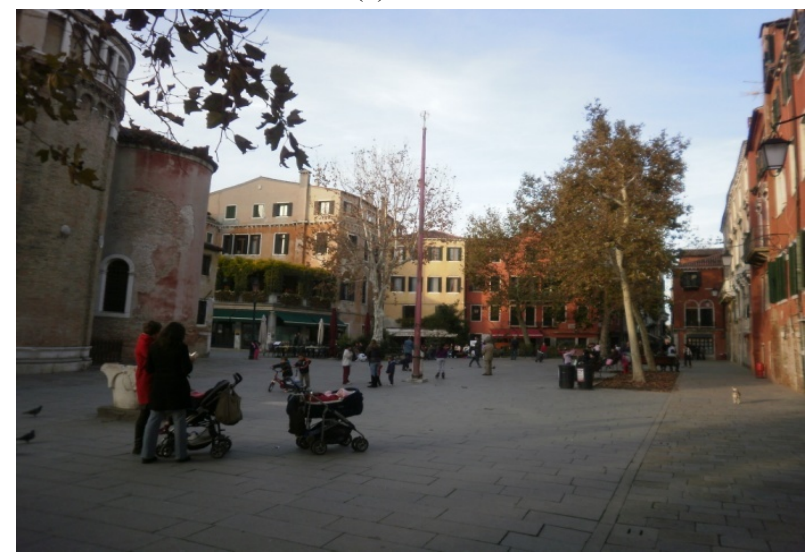

(c)

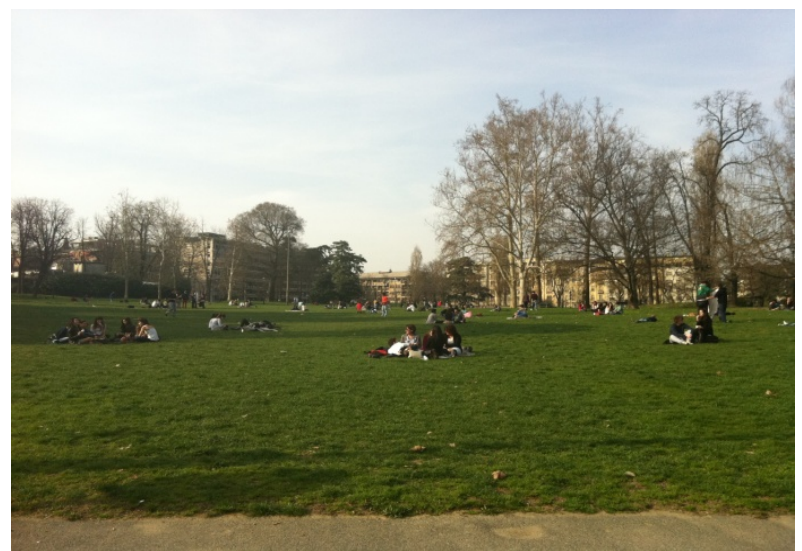

(b)

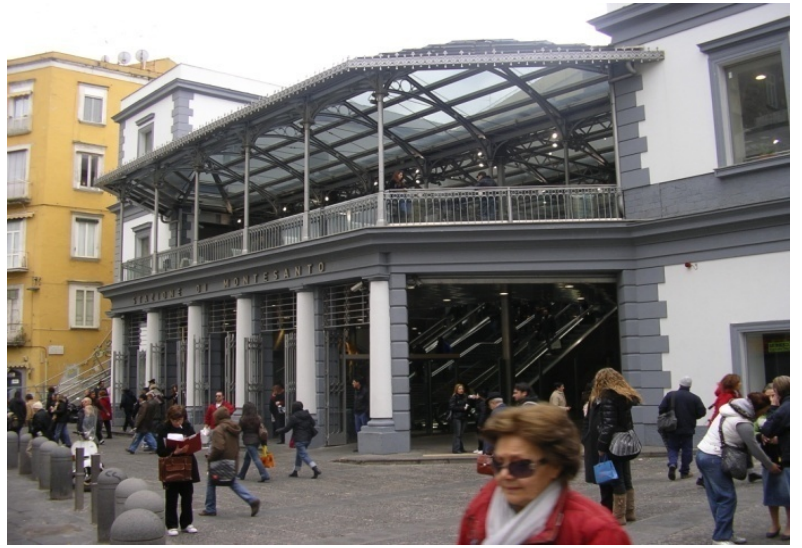

(d)

Fig. 1 The European city: (a) Commercial areas in the city centre of Eltville am Rhein (2008); (b) Castle Valentino Park in Turin (2011); (c) a square in Venice (2010); (d) the refurbished transport node of Montesanto in the historical centre of Naples (2009) (Photomontage by the authors).

From the environmental point of view, the residential and commercial balance in each area is a fundamental tool in securing a less car-oriented living model, as small retailers allow residents to meet their everyday needs by walking, thus, it represents a real and proper pillar in ensuring a sustainable urban lifestyle [27]. Furthermore, the link between small retailers and niche local production helps to ensure a more consistent and efficient supply chain, avoiding useless freight transportation costs, as well as reinforcing the relationship between the urban and rural environments [28].

Although these are remarkable and valuable features in the traditional European urban model, nowadays the changes in the international retail organization system are deeply impacting on the commercial functions of some urban areas. In particular, shopping malls and other large shopping centres present potential forces for dramatically reshaping the urban and suburban landscapes.

The research project, starting from the theoretical perspective described, aims at defining a participatory process to physical rehabilitation and social-economics regeneration centred on the enhancement of local art-and-crafts and retail traditions. The participatory process needs to be developed through involving local stakeholders such as: local authorities, entrepreneurs, retailers and artisans, representatives of local services, developers and planners, academics involved in research and education activities related to the area and representatives of local communities.

The conceptual framework consists of the possibility of merging urban design, community 
planning and economic procedures in order to build a new tool for renovating degraded public spaces and improving the attractiveness and accessibility of deprived urban areas by focussing on the high potential of local commercial activities. The research can assist policy-makers in coping with the needs of urban regeneration by setting up an analytical process to understand how a public-private partnership oriented to sustain local retail can be both market-led and social-led.

In the 1990s, the PPPs (public-private partnerships) have been considered as a key tool of public policy across the world [29]. In some cases, PPP (public-private partnership) can be considered as a cooperation between public and private sectors for developing services through risk and cost sharing. In other definitions, PPPs are informed on a mutual commitment between a public sector organization with any other organization: from non-profit NGOs to private companies market-led. As concern the balance of roles among partners, in PPP's both public and private parties share costs, revenues and responsibilities [30]. There are different forms of mutual commitment, of cost and revenue sharing and of subjects participant in PPPs oriented to regeneration processes [31]. In Italy in the 1990s, the planning culture has been massively interested with the integrated programs experience [32], and the definition of partnerships between local administrations (such as city council) and developers and other investors on the private side.

The research starts by highlighting integrated approaches related to credit access, local resources promotion, job creation, typical retail protection and community engagement - in order to understand how the territorial milieu can contribute to create the necessary critical mass for improving local urban regeneration initiatives [33].

In so doing, the development of the case study approach has been conducted under the umbrella of the Local Action Plan implemented within the framework of the CTUR and Hero projects of the URBACT II Programme in Naples.

\section{Case Study Analysis: The Local Action Plan of Naples Città Bassa}

The research here presented has been developed along diverse routes for empirical applications. In particular, two projects guided by local administrations and oriented to make possible a wide public-private partnership have been chosen to cross the theoretical premises with a case study approach. The projects "Cruise activity and the recovery of urban and harbour building heritage: strong elements of the common interest of sea towns to develop and strengthen the urban tourism sector" (CTUR) and "Heritage as Opportunity" (Hero) of the URBACT II Programme [34] have been both developed (2008-2011) by a network of European cities. The core idea of the first one has been to improve competitiveness and liveability of port cities through the waterfront revitalisation (including derelict industrial areas) in an overall approach of the port city development, creating a mix between maritime and urban activities within the framework of an integrated approach of sustainable development. The second project - dealing with the challenging management of historic towns in Europe-focuses on heritage cities throughout Europe, in order to enhance balance between the safeguarding of heritage and the development of the city, taking heritage as an economic driver. These projects are both completed and are now in the process of being implemented in the local policies and are the base of the new projects promoted by the Neapolitan City Council in order to deepening the concept of land consumption in the historic centre.

Briefly, Naples can be considered one of the prominent ancient settlements in Europe and part of the Mediterranean basin (Table 1). Its historic centre is a unique example of architectural stratification through the centuries and is still a vibrant catalyst of 
mixed activities without any museumification phenomena. Along with these positive aspects there are many problems, such as the high population density, the low education indexes, the severe status of the labour market linked to the lack of private activities and job creation initiatives, the presence of criminal organizations and the strong rehabilitation needs of the built environment, including the cultural heritage.

The complexity of this local scenario of resources and challenges is the humus for nourishing the local initiatives we have chosen as paramount cases to be described [35].

The first step has been the definition of the case study domain in terms of location, size, functional organization and general characteristics. Through the dialogue with the Urban Planning Department of the City of Naples, the active observations in different daytimes, weekdays and seasons as well as the discussion with local stakeholders and scholars in charge, a specific area involved in these comprehensive projects has been chosen in order to address the topics of the research.

The coexistence in the same area of various urban planning and management tools, of several UE-funded initiatives as well as of grassroots movements and of traditional local economic activities can be considered the ideal scenario for developing a complex participatory process of urban regeneration to be tested and generalized. The research in progress here introduced has been developing in parallel and-on some topics - in cooperation with the planners in charge for the cited URBACT projects conducted by the City of Naples (Table 2).

The area of Città Bassa, despite having previously had a strong commercial character, suffers since the end of the Second World War relative neglect and gradual decay. In this context, some relevant key issues can be pointed out with regards to: the physical aspects such as location, accessibility, built environment conditions, cultural issues such as historical heritage, monuments, arts and crafts traditions; and social scenario in terms of social deprivation indices (Table 3).

The work is premised on enhancing local revitalization and regeneration processes by focussing on the potential of an integrated approach to commercial activities, among the key issues related to the urban revitalization of the historical urbanscape. This is to be addressed in Naples by meeting the needs of different stakeholders - the linkage with the cited URBACT projects is "to secure traditional shops and retail trade structures as these ones are struggling to survive and to set up new governance structures for a better coordination of the revitalization activities" [34]. The focus area for Hero projects is Piazza Mercato, which is connected to an overall URBACT LAP named "Città Bassa" [34] included in a comprehensive intervention called "The waterfront of the historic centre and port area from piazza Municipio to piazza Mercato: a sustainable development through the improvement of the cruise tourism impact", which also concerns the LAP of the URBACT Thematic Network CTUR (Cruise Traffic and Urban Regeneration) lead by the City of Naples [36].

The area of Città Bassa of Naples reflects all the issues, criticisms and potentiality related to the integration of typical handicrafts, dense residential uses, traditional commercial activities and the historical character of public places. This wide and articulated area lies between the port and the historical centre which has been listed as a World Heritage Site by UNESCO since 1995 (Fig. 2).

The study area is included in the range of influence of the Local Action Plan built by the city with the help of its LSG (local support group), within the framework of the URBACT projects. The LSG as defined by Hero is to support the development and implementation of the Integrated Cultural Heritage Management Plan, which is "oriented towards the needs of the historic urban area and its users, offers the unique opportunity to bring the different stakeholders 
Table 1 Naples at a glance.

\begin{tabular}{ll}
\hline Classification & Properties \\
\hline Location & Capital of the Region of Campania-Southern Italy \\
First settlement & VI century B.C. as a Greek settlement \\
Population & $1,004,500$ inhabitants (City Council of Naples, census 2001) \\
Pop. density & 8,556 inh/sq km (City Council of Naples, census 2001) \\
Unemployment rate & $31.39 \%$ (City Council of Naples, census 2001) \\
Income per capita & $€ 25,565.81$ (Finance Ministry, 2009) \\
Historic centre & UNESCO recognizes the OUV (outstanding universal value) of the historic centre of Naples (1995) \\
\hline
\end{tabular}

Table 2 Plans and programmes which coexist in the study area.

\begin{tabular}{ll}
\hline Plans and programmes & Study area \\
\hline & DOS (Strategic Guidance Document) \\
& Integrated Urban Plan EUROPE for the historic centre of Naples (PIU EUROPA) \\
They connected to the & Grande Programma UNESCO (UNESCO Great Programme) \\
ERDF 2007-2013 & Strategic Plan of Naples \\
& Hero "Naples Historic Centre World Heritage Site Management Plan (WHSMP)" \\
& "Project of renewal of Borgo Orefici” under 2000-2006 ERDF Funds \\
\hline
\end{tabular}

Table 3 Città Bassa: some relevant aspects.

\begin{tabular}{ll}
\hline Classification & Properties \\
\hline Location & Enclave between the port area and the historic centre UNESCO WHS \\
\hline \multirow{3}{*}{ Accessibility } & 15 km from Capodichino International Airport \\
& Near the Central Railway Station \\
& Served by four metro stations (2 of those need to be completed) \\
& Near the local and regional maritime transportation nodes of Beverello Quay and Porta di Massa Quay \\
\hline & Porta Nolana gate of the ancient city walls \\
& The renaissance church of SS. Cosma e Damiano \\
Historical heritage & The ruins of Castel del Carmine \\
& The baroque church of Santa Maria del Carmine \\
& Sant'Eligio Maggiore Church of the Angevin period dated 1270 \\
\hline \multirow{3}{*}{ Art and crafts tradition } & Borgo degli Orefici (goldsmith quarter) since the fourteenth century \\
& Piazza Mercato Old Marketplace \\
& Antiche Botteghe tessili (textile market) \\
& Typical handmade street food \\
\hline \multirow{3}{*}{ Social deprivation } & Unemployment rate (Mercato district 38.01\%, Pendino district 40.37\%) \\
& Illegal immigration \\
& Hidden and informal economic activities \\
\hline \multirow{3}{*}{ Built environment } & Low level of housing maintenance and technological retrofitting \\
& Abandoned and decayed public places \\
& Lack of spaces for pedestrian uses due to cul-de-sacs, squares transformed in parking areas, inefficient \\
& street lighting, abandoned ground floors (38\% unused sqm-source Si.Re.Na Company) \\
& Buildings which provide physical and visual barriers between the area and the waterfront
\end{tabular}

together” [34]. The Neapolitan LSG has been formed as the first step of the URBACT projects and has become the main interlocutor of the different kinds of local initiatives such as research fieldworks, entrepreneurships, training and programmes for the control against informal and hidden economy.

The fieldwork here presented has been oriented to:

- Collect, analyse and compare the initiatives promoted within the EU-funded projects CTUR and Hero with the other top down initiatives promoted by the City Council of Naples;

- Develop a session of active observations, informal interactions with people met in the area, morphological analysis;

- Participate in focus groups, local initiatives, meetings with local stakeholders; 
- Discuss with local stakeholders the results of the LAP activities and the relevant questions emerged through participation in the activities of the LSG.

The results of this fieldwork could be summarized in the general idea that the LAP (Local Action Plan) of Naples Città Bassa could become an experience of paramount importance due to its mixed and complex character (Table 4). Focussing not only on social indices and economic issues, the added value of the LAP can be considered the capacity of integrating both the approaches: built environment and historic heritage rehabilitation on the one hand and economic strategies on the other. Within the LAP of Naples Città bassa emerges a strategic approach in focusing on the reconnection of the historical city centre with the harbour as engine for enhancing the vitality of the commercial district included in the area. The economic stakeholders (retail consortia, artisan consortia, shipping developers, building developers) suggested to enhance the LAP through collecting resources in order to support the specific rehabilitation projects included in the plan. The priorities emerged are: the development of sustainable tourism, the creation of business incubators related to the traditional artisanal and retail activities of the area, the increasing of commercial attractiveness through enhancing accessibility to the area, and job creation in specialized fields. From both the economic and social side, the stakeholders involved have identified as result obtained by the LAP the impact achieved at the local level by transferring the knowledge acquired in the URBACT process to local policies, programmes and actors. This has been accomplished by scaling-up some of the action plans at the policy level and integrating them into mainstream services, as well as by securing funding through the Operational Programmes of the ERDF (European Regional Development Fund) for their implementation (Table 5). Every subject interviewed agrees that the process has also contributed to creating new partnerships between
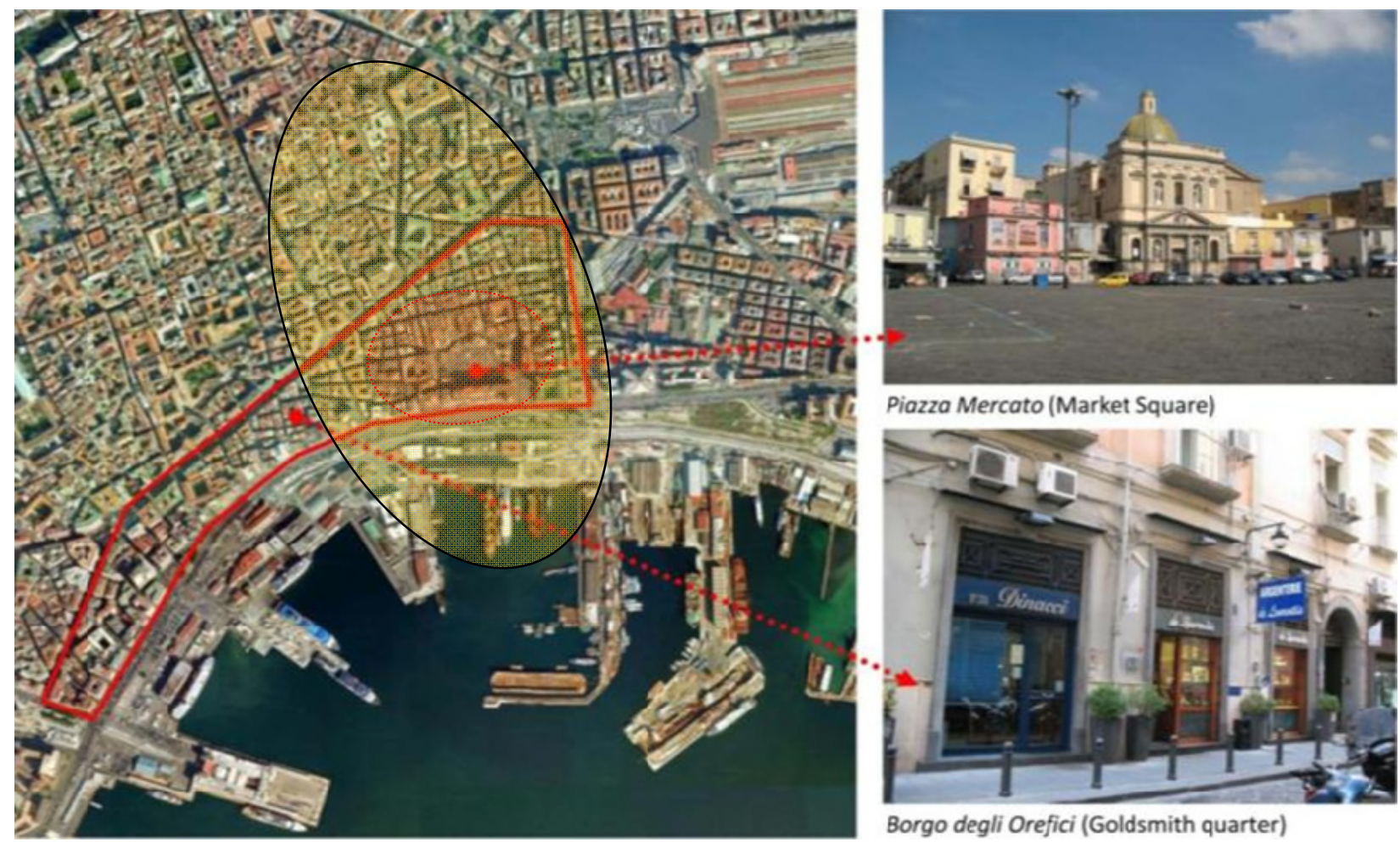

Piazza Mercato (Market Square)

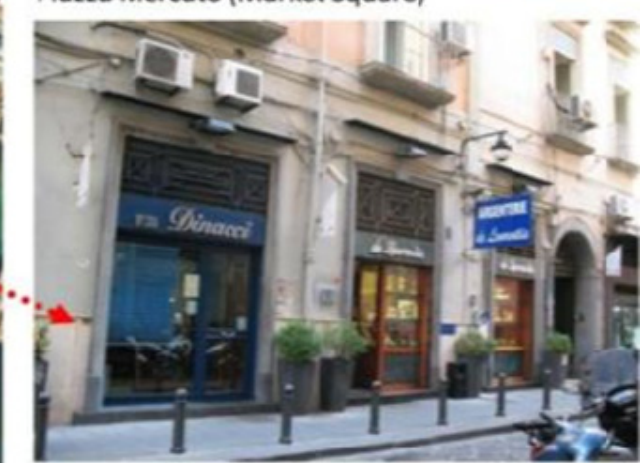

Borgo degli Orefici (Goldsmith quarter)

Fig. 2 The study area of Città Bassa of Naples and Piazza Mercato (Courtesy Stefania Oppido). 
Table 4 Città Bassa LAP: main aims and objectives.

\begin{tabular}{ll}
\hline No. & Main aims and objectives \\
\hline 1 & Requalification of the waterfront monumental area and nearby historic urban area \\
2 & Refunctionalization of the city and the port heritage \\
3 & Maximize the economic and social impacts of the projects \\
4 & Support the social and economic development of the "Città Bassa" quarter based on historical activities \\
\hline
\end{tabular}

Table 5 Città Bassa LAP: flagship projects investments (CTUR and Hero).

\begin{tabular}{llcl}
\hline Projects & Responsible & Funds allocated & Source \\
\hline Cultural heritage safeguarding_-building restoration & & & \\
Old Monastery Carminiello (School) & City of Naples & $3,000,000$ & ERDF 2007/2013 \\
S.Eligio Monastery & & $2,500,000$ & \\
Borgo Orefici requalification & SiReNa & $17,670,000$ & Public/private \\
S.Maria Portosalvo Church & Private & $1,200,000$ & Private \\
Public places requalification & City of Naples & $5,140,000$ & ERDF 2007/2013 \\
Requalification of complex ambit in the area & & $10,000,000$ & ERDF 2007/2013 \\
Underground parking and requalification of related areas & & $13,500,000$ & ERDF 2007/2013 \\
Business incubator for goldsmith and textile activities & City of Naples & $1,000,000$ & ERDF 2007/2013 \\
& Private consortia & $4,203,491$ & Private funds \\
Tramlines and requalification of via marina & City of Naples & $13,997,299$ & ERDF 2000/2006 \\
Shuttle connection to the maritime nodes & Port Authority of & 750,000 & Public/private funds \\
& Naples & Port Authority of
\end{tabular}

Sources: Hero Flagships Projects 2011 and CTUR Naples Local Action Plan [37].

different levels of government and the involvement and participation of private stakeholders in the development of the project. The LAP has been developed through the active participation of different categories of local stakeholders, designing a new possible structure of PPP.

\section{Conclusions}

The complex and articulated scenario of PPP tools offers the possibility of identify a possible dynamic system of relationships between subjects, actions, resources, roles and evaluation of the results. In particular, the case study approach is needed to design a sort of fuzzy-architecture of the partnership models aimed at facilitating local private and public initiatives within the framework of the common interest of generating social and economic enhancement. A bottom up approach, oriented not only to collect demands and needs from the territory but also to encourage private initiatives, start-ups, non-profit organizations, and other forms of investments, will be elaborated and discussed with local stakeholders.

Starting from the virtuous process launched within the framework of the URBACT LAP here analysed and applying the methodological premises of the CLUDs project, an adaptive model of urban regeneration based on commercial activities is currently being defined - in cooperation with the local stakeholders involved in the transformations of the study area.

Evidences from the fieldwork states that in specific conditions local traditional commercial areas could play an important role as drivers of urban regeneration and cultural enhancement. The conditions identified are:

- The former or current presence of local art \& craft and/or cultural traditions that could be the media for enhancing the collective sense of belonging to the area and building the critical mass for developing a regeneration process;

- The activation of bottom up (predominantly private) and/or top down (predominantly public) 
projects oriented to support local initiatives in terms of social activation, job creation, place branding, public places rehabilitation;

- The participation of local economic and social stakeholder to the decision making process in order to better address priorities and resources.

In the context analysed, the LAP has been considered an important instrument for merging together the above conditions and for encouraging the dialogue between the stronger stakeholders of the LAP area, such as the Port Authority, the City Council and the other public actors involved on one side, and the communities, the arts and crafts private consortia, the developers and the port operators on the other side. By setting up the local support group, the URBACT projects acting in the area have created a positive process: first, the initiatives developed by public bodies started the auditioning process and the collection of resources; subsequently, private bodies and civil society have become part of the process.

As we can see, in the LAP experiences analysed, the initiative starts with the involvement of public bodies whose activites are primarily oriented to identify priority for public investments and to engage other public and private stakeholders. This process has been developed by the City of Naples and the LSG using a wide participatory process involving different categories of city-users, producing a huge data and information collection from the territory, providing a big effort in terms of sourcing and integration of financial resources and involving different categories of city-users.

The institutional architecture of the partnerships between public and private actors in the area and the relationships between these partnerships and the projects funded in the area depends on the National Operational Programme of the Campania Region funded within the ERDF 2007/2013. The LAP can be considered the process for bringing together the local initiatives with the main flagship projects funded by the public sector, in order to enhance the results of this bottom up approach by creating the humus for nourishing the non-profit private initiatives of urban regeneration driven by the development and rehabilitation of commercial areas in a wide profitable and marketable way.

The next step of this ongoing research should be, according to the CLUDs rationale, the investigation of the potentiality of the territorial milieu in enhancing the building capacity of the commercial local districts in the city core.

\section{Acknowledgments}

This presentation draws from the cooperation between the research program CLUDs funded within the framework of the EU IRSES Marie Curie 7FP and the Urban Planning unit of the National Research Council of Italy (CNR-IRAT).

\section{References}

[1] A. Madanipour, Whose Public Space? International Case Studies in Urban Design and Development, Routledge, London, 2010.

[2] M. Carmona, S. Tiesdell, T. Heath, T. Oc, Public Places Urban Spaces: The Dimensions of Urban Design, Routledge, New York and London, 2010.

[3] A. Madanipour, G. Cars, J. Allen, Social exclusion and space, in: R.T. LeGates, F. Stout (Eds.), The City Reader, Routledge, New York and London, 2011.

[4] M. Augé, Non-lieux, Editions Seuil, Paris, 1992.

[5] H. Shaftoe, Convivial Urban Spaces: Creating Effective Public Places, Earthscan, London, 2008.

[6] P. Healey, Collaborative Planning: Shaping Places in Fragmented Societies, Macmillan, London, 1997.

[7] N. Waters, The Community Planning Handbook, Earthscan, London, 2000.

[8] H. Sanoff, Community Participation Methods in Design and Planning, John Wiley and Sons, New York, 2000.

[9] S.R. Arnstein, A ladder of citizen participation, Journal of American Planning Association 35 (4) (1969) 216-224.

[10] S. Sassen, The Global City, Princeton University Press, Princeton, 1991.

[11] T. Beatley, K. Manning, The Ecology of Place: Planning for Environment, Economy and Community, Island Press, Washington DC, 1997.

[12] R.K. Yin, Case Study Research, Design and Methods, 3rd ed., Sage Publications, London, 2003. 
[13] CLUDs Commercial Local Urban Districts, Research Concept, http://www.cluds-7fp.unirc.it/concept.php (accessed Apr. 10, 2011).

[14] F. Choay, P. Merlin, Dictionary of Urban Planning and Management, Gallimard, Paris, 2000. (in French)

[15] A. Amin, Collective culture and urban public space, City 12 (1) (2008) 5-24.

[16] D.W. Brinkerhoff, J.M. Brinkerhoff, Public private partnerships: Perspectives on purposes publicness and good governance, Public Administration and Development 31 (1) (2011) 2-14.

[17] M. Crang, Public space, urban space and electronic space: Would the real city please stand up?, Urban Studies 37 (2) (2000) 301-317.

[18] J. Habermas, The Structural Transformation of the Public Sphere: An Inquiry into a Category of Bourgeois Society, Hermann Luchterhand Verlag, Germany, 1989.

[19] S. Carr, M. Francis, L. Rivlin, A. Stone, Public Space, Cambridge University Press, Cambridge, 1993.

[20] P. Howell, Public space and the public sphere: Political theory and the historical geography of modernity, Society and Space 11 (1993) 303-322.

[21] Naples Hero Local Action Plan 2011, http://urbact.eu/fileadmin/Projects/HERO/projects_media /LAP_NAPLES_FINAL.pdf (accessed Apr. 5, 2012).

[22] K. Worpole, Here Comes the Sun: Architecture and Public Space in Twentieth Century Europe, Reaktion Books, London, 2000.

[23] R. Segal, E. Verbakel, Cities of Dispersal, Architectural Design, Wiley, New York, 2008.

[24] J. Gehl, A. Matan, Two perspectives on public spaces, Building Research \& Information 37 (2009) 106-109.

[25] J. Gehl, Life between Buildings: Using Public Space, 5th ed., Arkitektens Forlag, Copenhagen, 2001.

[26] D. McNeill, Fine grain, global city: Jan Gehl, public space and commercial culture in central Sidney, Journal of Urban Design 16 (2) (2011) 161-178.

[27] Z.M. Akkar Ercan, Public spaces of post-industrial cities and their changing roles, METU (Middle East Technical University) Journal of the Faculty of Architecture 24 (1) (2007) 115-137.

[28] M. de Martino, A. Marasco, A. Morvillo, Supply chain integration and port competitiveness: A network approach, in: P. Evangelista, A. McKinnon, E. Sweeney, E. Esposito (Eds.), Supply Chain Innovation for Competing in Highly Dynamic Markets: Challenges and Solutions, IGI Global, London, 2012.

[29] S.P. Osborne, Public-Private Partnerships: Theory and Practice an International Perspective, Routledge, New York and London, 2000.

[30] M. Bult-Spierung, Strategic Issues in Public Private Partnerships: An Alternative Perspective, Blackwell Publishing, London, 2006.

[31] CLUDs Report 2012, Economic Development Strategies, http://www.cluds-7fp.unirc.it/docs/deliverables/wp1_final .pdf (accessed May 23, 2013).

[32] M. Ricci, P. Avarello, From the Complex Programmes to the Integrated Policies for Development, INU (National Institute of Urban Planning), Roma, 2000. (in Italy)

[33] A. Ball, Synergy in urban regeneration partnerships: property agents' perspectives, Urban Studies 40 (11) (2003) 2239-2253.

[34] Naples Hero Local Action Plan 2011, http://urbact.eu/fileadmin/Projects/HERO/projects_media /LAP_NAPLES_FINAL.pdf (accessed Apr. 5, 2012).

[35] J. Gaber, S.L. Gaber, Qualitative Analysis for Planning and Policy: Beyond the Numbers, American Planning Association, Chicago, 2007.

[36] Naples CTUR Local Action Plan 2011, http://urbact.eu/fileadmin/Projects/CTUR/outputs_media/ CTUR_Report-Finale-IT_def.pdf (accessed Mar. 6, 2012).

[37] Naples CTUR Local Action Plan 2011, http://urbact.eu/fileadmin/Projects/CTUR/outputs_media/ light_def_LAP_CTUR_Naples_Port_Authority_En.pdf (accessed Jan. 15, 2012). 